Article

\title{
Electrochemical Deposition of Fe-Co-Ni Samples with Different Co Contents and Characterization of Their Microstructural and Magnetic Properties
}

\author{
Van Cao Long ${ }^{1}\left(\mathbb{D}\right.$, Umut Saraç ${ }^{2, *(\mathbb{D})}$, Mevlana Celalettin Baykul ${ }^{3} \mathbb{D}$, Luong Duong Trong ${ }^{4}$, Ştefan Ţălu $5, *(\mathbb{D}$ \\ and Dung Nguyen Trong $1,6, * \mathbb{D}$
}

check for updates

Citation: Cao Long, V.; Saraç, U.; Baykul, M.C.; Trong, L.D.; Ţălu, Ş.; Nguyen Trong, D. Electrochemical Deposition of Fe-Co-Ni Samples with Different Co Contents and

Characterization of Their Microstructural and Magnetic Properties. Coatings 2022, 12, 346. https://doi.org/10.3390/ coatings 12030346

Academic Editors

Matic Jovičević-Klug,

Patricia Jovičević-Klug and

László Tóth

Received: 1 February 2022

Accepted: 3 March 2022

Published: 6 March 2022

Publisher's Note: MDPI stays neutral with regard to jurisdictional claims in published maps and institutional affiliations.

Copyright: (C) 2022 by the authors. Licensee MDPI, Basel, Switzerland. This article is an open access article distributed under the terms and conditions of the Creative Commons Attribution (CC BY) license (https:// creativecommons.org/licenses/by/ $4.0 /$ )
1 Institute of Physics, University of Zielona Góra, Prof. Szafrana 4a, 65-516 Zielona Góra, Poland; vancaolong2020@gmail.com

2 Department of Science Education, Bartın University, Bartın 74100, Turkey

3 Department of Metallurgical and Materials Engineering, Eskişehir Osmangazi University, Eskişehir 26480, Turkey; cbaykul@ogu.edu.tr

4 Department of Electronic Technology and Biomedical Engineering, Hanoi University of Science and Technology, Hanoi 100000, Vietnam; luong.duongtrong@hust.edu.vn

5 The Directorate of Research, Development and Innovation Management (DMCDI), Technical University of Cluj-Napoca, 15 Constantin Daicoviciu St., 400020 Cluj-Napoca, Romania

6 Faculty of Physics, Hanoi National University of Education, 136 Xuan Thuy, Cau Giay, Hanoi 100000, Vietnam

* Correspondence: usarac@bartin.edu.tr (U.S.); stefan.talu@auto.utcluj.ro (T.S.); dungntsphn@hnue.edu.vn (D.N.T.)

\begin{abstract}
In this study, to explore the effect of Co contents on the electroplated $\mathrm{Fe}-\mathrm{Co}-\mathrm{Ni}$ samples, three different $\mathrm{Fe}-\mathrm{Co}_{33}-\mathrm{Ni}_{62}, \mathrm{Fe}-\mathrm{Co}_{43}-\mathrm{Ni}_{53}$, and $\mathrm{Fe}-\mathrm{Co}_{61}-\mathrm{Ni}_{36}$ samples were electrochemically grown from Plating Solutions (PSs) containing different amounts of Co ions on indium tin oxide substrates. Compositional analysis showed that an increase in the Co ion concentration in the PS gives rise to an increment in the weight fraction of $\mathrm{Co}$ in the sample. In all samples, the co-deposition characteristic was described as anomalous. The samples exhibited a predominant reflection from the (111) plane of the face-centered cubic structure. However, the $\mathrm{Fe}-\mathrm{Co}_{61}-\mathrm{Ni}_{36}$ sample also had a weak reflection from the (100) plane of the hexagonal close-packed structure of Co. An enhancement in the Co contents caused a strong decrement in the crystallinity, resulting in a decrease in the size of the crystallites. The $\mathrm{Fe}-\mathrm{Co}_{33}-\mathrm{Ni}_{62}$ sample exhibited a more compact surface structure comprising only cauliflower-like agglomerates, while the $\mathrm{Fe}-\mathrm{Co}_{43}-\mathrm{Ni}_{53}$ and $\mathrm{Fe}-\mathrm{Co}_{61}-\mathrm{Ni}_{36}$ samples had a surface structure consisting of both pyramidal particles and cauliflower-like agglomerates. The results also revealed that different $\mathrm{Co}$ contents play an important role in the surface roughness parameters. From the magnetic analysis of the samples, it was understood that the $\mathrm{Fe}-\mathrm{Co}_{61}-\mathrm{Ni}_{36}$ sample has a higher coercive field and magnetic squareness ratio than the $\mathrm{Fe}-\mathrm{Co}_{43}-\mathrm{Ni}_{53}$ and $\mathrm{Fe}-\mathrm{Co}_{33}-\mathrm{Ni}_{62}$ samples. The differences observed in the magnetic characteristics of the samples were attributed to the changes revealed in their phase structure and surface roughness parameters. The obtained results are the basis for the fabrication of future magnetic devices.
\end{abstract}

Keywords: cauliflower-like agglomerates; Co contents; crystallinity; Fe-Co-Ni thin film samples; magnetic properties; phase structure; pyramidal particles; roughness parameters

\section{Introduction}

Nanostructured ferromagnetic materials in the form of thin films are widely used in many technological applications and attract great attention because of their good physical and magnetic features [1-5]. To date, many physical and chemical growth techniques have been developed that are utilized in the production process of magnetic thin film samples. Among the growth techniques developed, the electrochemical deposition technique has 
been successfully used in computer read/write heads and Micro-ElectroMechanical Systems (MEMS) applications due to its unique features [1,3,6-12]. It is well known that ternary ferromagnetic alloy films are interesting soft magnetic materials due to their high saturation magnetization and low coercive field $[4,6]$. The conducted studies showed that the $\mathrm{Fe}, \mathrm{Ni}$, and $\mathrm{Co}$ components in binary $\mathrm{Ni}-\mathrm{Co}, \mathrm{Ni}-\mathrm{Fe}$ and $\mathrm{Fe}-\mathrm{Cu}$ and ternary $\mathrm{Ni}-\mathrm{Co}-\mathrm{Cu}, \mathrm{Ni}-\mathrm{Fe}-\mathrm{Cu}$, $\mathrm{Co}-\mathrm{Fe}-\mathrm{Cu}$ and $\mathrm{Fe}-\mathrm{Co}-\mathrm{Ni}$ magnetic materials grew by the electrochemical deposition technique on Indium Tin Oxide (ITO) covered glass substrates which can be tuned by controlling the $\mathrm{Fe}, \mathrm{Ni}$ and $\mathrm{Co}$ ion concentrations in the Plating Solutions (PSs), respectively [13-21]. However, the relative compositions of $\mathrm{Co}$ and Fe components in the samples were found be higher than those in the PSs for different electroplating parameters [6,13,14,16-24], which is in good agreement with the definition defined by Brenner [25]. In recent years, scientists have flexibly used a variety of methods to study the structural, mechanical, and magnetic properties of nanomaterials and thin films. With the simulation method, the influence of size, heating rate, temperature and annealing time has been successfully studied on the structure, electronic structure, phase transition and mechanical properties of metal $\mathrm{Ni}$ [26-28], Fe [29], Al [30,31], Alloy AuCu [32,33], CuNi [34-36], NiAu [37], FeC [38], $\mathrm{FeNi}[39,40], \mathrm{AgAu}[41]$, AlNi [42], and $\mathrm{NiCu}[43]$.

In addition, with the magnetism of nanomaterials and thin films, the influence of nanoparticle size and shell thickness has been successfully studied on the Curie Tc phase transition temperature of Fe nanoparticles [44], the influence of external magnetic field and size on the temperature Neel TN phase transition of $\mathrm{Fe}_{2} \mathrm{O}_{3}$ thin films [45]. The obtained results show that the Neel TN transition temperature is always smaller than the Curie Tc phase transition temperature, the cause of this phenomenon is due to the Topo effect. With the experimental method, the authors have successfully studied the effects of Fe ion concentration in the PS. Furthermore, the deposition potential applied during electroplating process on the chemical composition, some physical properties, and magnetic characteristics of ternary ferromagnetic thin film samples were investigated [21,24]. These experimental studies clearly demonstrated that the surface performance, magnetic and structural characteristics were affected significantly by the deposit composition caused by the variation of the electroplating parameters $[21,24]$. On the other hand, in a former study, $\mathrm{Fe}-\mathrm{Co}-\mathrm{Ni}$ deposits were electrochemically manufactured on titanium sheets from a chloride-sulfate-tartaric acid medium at different $\mathrm{Co}^{2+} / \mathrm{Ni}^{2+}$ ion ratios [46]. In another study, $\mathrm{Fe}-\mathrm{Co}-\mathrm{Ni}$ films were electrochemically fabricated on copper substrates from an ammonium-chloride-based PS at different $\mathrm{Co}^{2+} / \mathrm{Ni}^{2+}$ ion ratios [47]. In addition, in a very recent study, nanocrystalline $\mathrm{Ni}-\mathrm{Co}-\mathrm{Fe}$ coatings were electroplated on copper plates from a sulfate-citrate PS at different $\mathrm{Co}$ ion concentrations [3]. To make magnetic $\mathrm{Fe}-\mathrm{Co}-\mathrm{Ni}$ thin films, researchers can use many methods such as evaporation and electrochemical deposition [48]. Among these, thin films obtained by the electrochemical deposition method have very high uniformity. However, in this work, $\mathrm{Fe}-\mathrm{Co}-\mathrm{Ni}$ samples were electroplated on ITO substrates and the Co contents in the samples were tuned by the amount of Co ion concentration in the sulfate-based PS. The structure, morphology, and magnetic characteristics of the resultant samples were discussed with respect to their Co contents. The results showed that the crystallinity, crystallite size, phase structure, particle shape, particle size, magnetic properties, and roughness parameters of the samples are strongly dependent on their Co contents. The obtained results will be applied in different fields of science and technology.

\section{Materials and Method}

The Fe-Co-Ni thin film samples were produced from PSs composed of Ni sulfate $(0.07 \mathrm{M})$, Fe sulfate $(0.0020 \mathrm{M})$, boric acid $(0.1 \mathrm{M})$, and various Co sulfate concentrations $(0.016 \mathrm{M}, 0.024 \mathrm{M}$ and $0.040 \mathrm{M})$. The samples were deposited galvanostatically at the same current density of $-10 \mathrm{~mA} / \mathrm{cm}^{2}$ from freshly prepared PSs ( $\mathrm{pH}$ value was $5.2 \pm 0.1$ and temperature was $22 \pm 1{ }^{\circ} \mathrm{C}$ ) without stirring. The electroplating processes were performed by employing a three-electrode system. A platinum sheet was utilized as a counter electrode, 
whereas a Saturated Calomel Electrode (SCE) was served as a reference electrode. The samples were grown on ITO coated glass substrates used as a working electrode. Before the plating process, the substrates were first rinsed in an acetone solution and then in ethanol solution. After that, the substrates were cleaned by an ultrasonic bath using deionized water. The crystal structure was defined by a Rigaku SmartLab X-Ray Diffractometer (XRD) (Rigaku Cooperation-Tokyo, Japan). The XRD measurements were carried out in the $2 \theta$ range between $40^{\circ}$ and $54^{\circ}$ at a scanning step of $0.01^{\circ}$ using $\mathrm{CuK}_{\alpha}$ radiation source. The compositional analysis was performed by an Energy Dispersive X-ray (EDX) spectroscopy. The X-ray diffraction beam is shined at the sample with a very narrow angle of incidence to increase the length of the X-ray beam that interacts with the thin film, keeping the sample stationary and rotating the receiver. Then the resulting diffraction beam appears on a concentric circle, recording the reflected beam intensity and first-order diffraction spectrum. An Oxford X-max 50 detector (Oxford Instruments, High Wycombe, UK) was used for the EDX measurements under an operating voltage of $20.00 \mathrm{kV}$. To study the surface structure, a Tescan MAIA3 Scanning Electron Microscopy (SEM) (TESCAN, Brno, Czech Republic) was used. The SEM measurements were done under the same operating voltage of $5.00 \mathrm{kV}$ at room temperature. The particle sizes were determined from the SEM images using a freely available image processing and analysis software (ImageJ) (Software version for imageJ is 1.8.0). The roughness parameters were determined using a Veeco Multimode V Atomic Force Microscopy (AFM) (Veeco Instruments İnc., Santa Barbara, CA, USA) and evaluated using a WSxM 5.0 develop 9.4 software package [49]. To reveal the effect of the Co contents on the coercive field and squareness ratio, magnetic measurements were carried out by means of a JDAW-2000D model Vibrating Sample Magnetometer (VSM) (Xiamen Dexing Magnet Tech. Co., Ltd., City-Country: Xiamen, China) at ambient temperature and pressure by applying the external magnetic field parallel to the sample plane.

\section{Results and Discussion}

This paper aimed to study the impact of the Co contents on the structure, morphology, and magnetic characteristics of the Fe-Co-Ni deposits. To obtain the samples with various Co contents, the samples were grown onto ITO-coated glass substrates from PSs comprising different concentrations of Co ions using the electrochemical deposition technique. The potential-time transient curves are given in Figure 1.

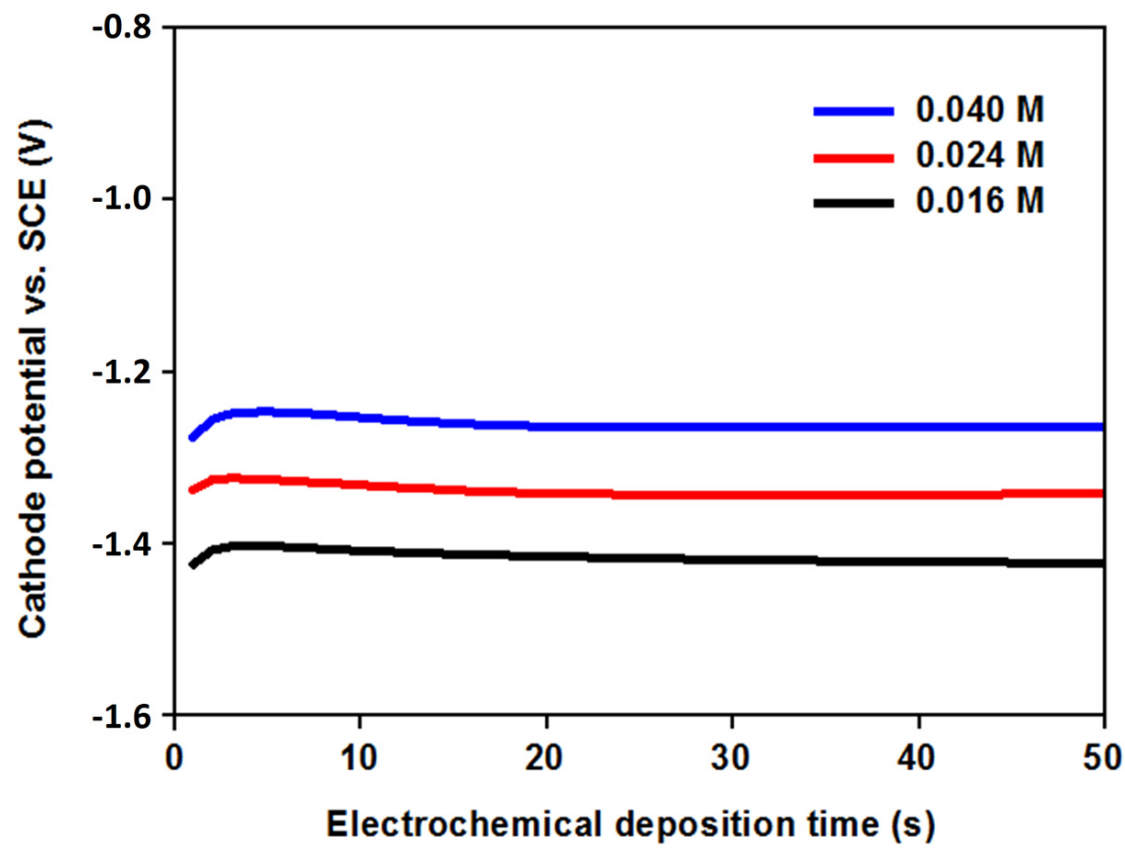

Figure 1. Potential-time transient curves of the samples electroplated at different ion concentrations of Co. 
From Figure 1, it was understood that the samples can be grown properly from PSs containing different concentrations of Co ions owing to their stable cathode potentials. On the other hand, the cathode potential was detected to be higher for the sample electrochemically deposited from the PS with $0.016 \mathrm{M}$ Co ion concentration compared to those determined for the samples deposited from PSs with 0.024 M and 0.040 M Co xml: confirmned with AE 1. keep email based on word 2. keep the ORCID 3. keep the format of not English for City in affs 4 . keep the hyphen in figures 5. keep the two "Figure 6 indicates the AFM images of the samples. The samples possessed globular particles of various sizes" in textion concentrations.

EDX analyses showed that the samples electrochemically grown from PSs with different concentrations of $\mathrm{Co}$ ions have different $\mathrm{Fe}, \mathrm{Co}$, and Ni compositions. The compositional differences are shown in Table 1.

Table 1. The EDX data, phase structure, mean crystallite size, roughness parameters, coercive field, and squareness ratio of the samples.

\begin{tabular}{|c|c|c|c|}
\hline & \multicolumn{3}{|c|}{ Co Ion Concentration (M) } \\
\hline & 0.016 & 0.024 & 0.040 \\
\hline Co (wt.\%) & 32.9 & 43.2 & 60.9 \\
\hline $\mathrm{Ni}(\mathrm{wt} . \%)$ & 62.4 & 52.7 & 35.7 \\
\hline Fe (wt.\%) & 4.7 & 4.1 & 3.4 \\
\hline Resultant sample & $\mathrm{Fe}-\mathrm{Co}_{33}-\mathrm{Ni}_{62}$ & $\mathrm{Fe}-\mathrm{Co}_{43}-\mathrm{Ni}_{53}$ & $\mathrm{Fe}-\mathrm{Co}_{61}-\mathrm{Ni}_{36}$ \\
\hline Phase structure & fcc & fcc & Fcc + hcp \\
\hline Mean crystallite size (nm) & 21.6 & 20.2 & 15.6 \\
\hline RMS roughness (nm) & 14.4 & 17.8 & 28.4 \\
\hline Average roughness (nm) & 11.0 & 14.0 & 21.8 \\
\hline Average particle size (nm) & $\sim 150$ & $\sim 14.0$ & $\sim 250$ \\
\hline Coercive field (Oe) & 36 & 51 & 121 \\
\hline Squareness ratio $(\%)$ & 9.2 & 17.6 & 23.6 \\
\hline
\end{tabular}

The sample grown from the PS with the lowest Co ion concentration of $0.016 \mathrm{M}$ contained the lowest Co contents (32.9 wt.\%), but the highest $\mathrm{Ni}(62.4 \mathrm{wt} . \%)$ and Fe (4.7 wt.\%) compositions. In contrast to that, the sample electrochemically deposited from the PS with the highest $\mathrm{Co}$ ion concentration of $0.040 \mathrm{M}$ included the highest Co contents (60.9 wt.\%), but the lowest $\mathrm{Ni}$ (35.7 wt.\%) and Fe (3.4 wt.\%) compositions. The Co, Ni, and Fe compositions of the sample fabricated from the PS with an intermediate Co ion concentration of $0.024 \mathrm{M}$ were $43.2,52.7$ and $4.1 \mathrm{wt}$ \% , respectively. In summary, as the Co ion concentration in the PS was increased, the weight proportions of $\mathrm{Ni}$ and Fe components decreased, while the weight proportion of the Co component in the Fe-Co-Ni samples increased. Thus, three different ternary $\mathrm{Fe}-\mathrm{Co}_{33}-\mathrm{Ni}_{62}, \mathrm{Fe}-\mathrm{Co}_{43}-\mathrm{Ni}_{53}$ and $\mathrm{Fe}-\mathrm{Co}_{61}-\mathrm{Ni}_{36}$ samples with different $\mathrm{Co}$ contents were fabricated. In recent studies $[3,50]$, it was reported that the Co contents in electrochemically manufactured $\mathrm{Ni}-\mathrm{Co}-\mathrm{Fe}$ coatings and $\mathrm{Co}-\mathrm{Fe}-\mathrm{Ni}$ alloying micropillars increased but the Fe and $\mathrm{Ni}$ compositions decreased as the $\mathrm{Co}^{2+}$ ion concentration in the PS increased. Similar results were also found in Fe-Co-Ni deposits electroplated in a former study [46], which was consistent with our results. On the other hand, in this work, the presence or absence of Anomalous Co-Deposition (ACD) was also explored. In this context, the relative $\mathrm{Co}, \mathrm{Ni}$, and Fe ion percentages in the PSs were compared to the relative $\mathrm{Co}, \mathrm{Ni}$, and Fe compositions in the samples.

As seen in Figure 2, the relative $\mathrm{Co}$ (Fe and $\mathrm{Ni}$ ) composition in the sample increased with increasing relative $\mathrm{Co}$ (Fe and $\mathrm{Ni}$ ) ion percentage in the PS. However, in all cases, the Co contents in the samples were determined to be higher than the Co ion percentage in the PSs (Figure 2a). The same phenomenon found for the Co component was also detected for 
the Fe component (Figure 2b). This revealed the preferential electrochemical deposition for the $\mathrm{Co}$ and Fe components. However, the relative Ni composition in the samples was found to be lower than the relative Ni ion percentage in the PSs (Figure 2c). This indicated that the reduction of Ni components was inhibited. Thus, it was understood that the ACD behavior took place for all Co ions in the PS. The order of ACD was also revealed via composition ratio value $(\mathrm{CRV})$.
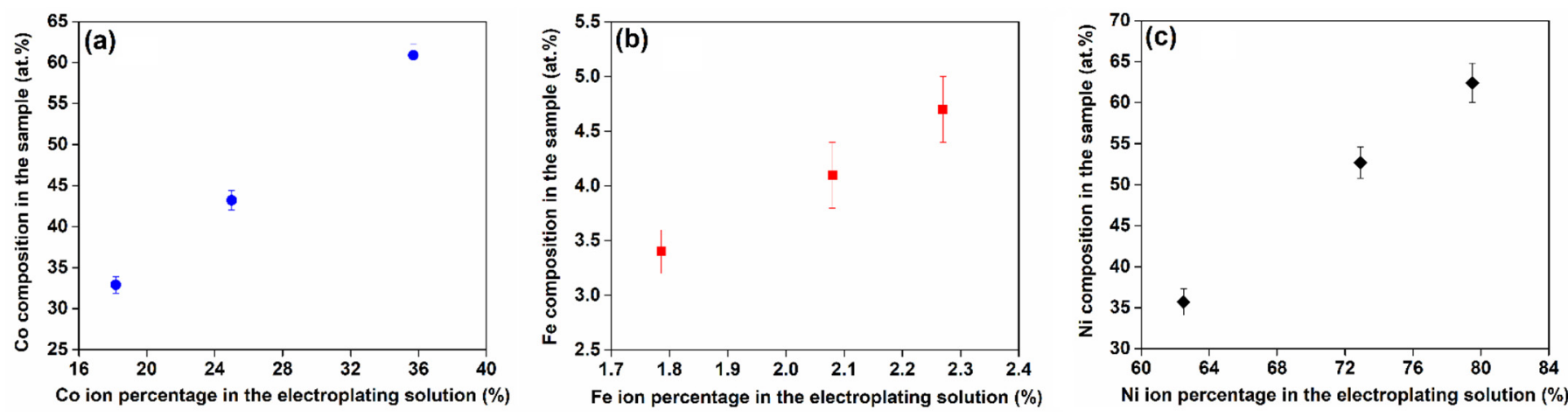

Figure 2. The relative $\mathrm{Co}(\mathbf{a}), \mathrm{Fe}(\mathbf{b})$, and $\mathrm{Ni}(\mathbf{c})$ composition in the samples against the relative $\mathrm{Co}(\mathrm{Fe}$ and Ni) ion percentage in the PSs.

The CRV for a Co component is described by the following expression [46].

$$
\mathrm{CRV} \text { for } \mathrm{Co}=\frac{\text { relative composition of Co in the sample }}{\text { relative ion concentration of Co in the PS }}
$$

The relative concentration of Co ions in the PS is given by the following expression:

$$
\text { Relative concentration of Co ions }=\frac{\left[\mathrm{CoSO}_{4}\right]}{\left[\mathrm{CoSO}_{4}+\mathrm{NiSO}_{4}+\mathrm{FeSO}_{4}\right]} \times 100
$$

The above procedure was also applied to calculate the $\mathrm{CRV}_{\mathrm{Fe}}$ and $\mathrm{CRV} \mathrm{Ni}_{\mathrm{Ni}}$. From the results of the analysis depicted in Figure 3, it was understood that the $C R V_{\mathrm{Fe}}$ and $C R V_{\mathrm{Co}}$ were higher than one, while the $C R V_{\mathrm{Ni}}$ was lower than one, revealing that the reduction rate of $\mathrm{Ni}^{2+}$ was significantly lower than the reduction rates of $\mathrm{Fe}^{2+}$ and $\mathrm{Co}^{2+}$ during the deposition process. This phenomenon confirmed the creation of ACD behavior, which is the characteristic feature for the electrochemical deposition of iron-group alloys. Furthermore, the reduction rate of $\mathrm{Fe}^{2+}$ was higher compared to the reduction rate of $\mathrm{Co}^{2+}$ as the $\mathrm{CRV}_{\mathrm{Co}}$ was lower than $\mathrm{CRV}_{\mathrm{Fe}}[3,6,19,24,46,51-53]$. Therefore, the degree of $\mathrm{ACD}$ characteristics of $\mathrm{Co}-\mathrm{Ni}$ was lower than $\mathrm{Fe}-\mathrm{Ni}$. In addition, the $\mathrm{CRV}_{\mathrm{Fe}} / \mathrm{CRV}_{\mathrm{Co}}$ ratio was determined to be lower than the $\mathrm{CRV}_{\mathrm{Co}} / \mathrm{CRV}_{\mathrm{Ni}}$ ratio, revealing that the order of $\mathrm{ACD}$ was $\mathrm{Fe}-\mathrm{Ni}>\mathrm{Co}-\mathrm{Ni}>$ $\mathrm{Fe}-\mathrm{Co}$ for all Co ion concentrations in the PS, which is in good agreement with the findings of conducted studies $[3,6,24,46]$. 


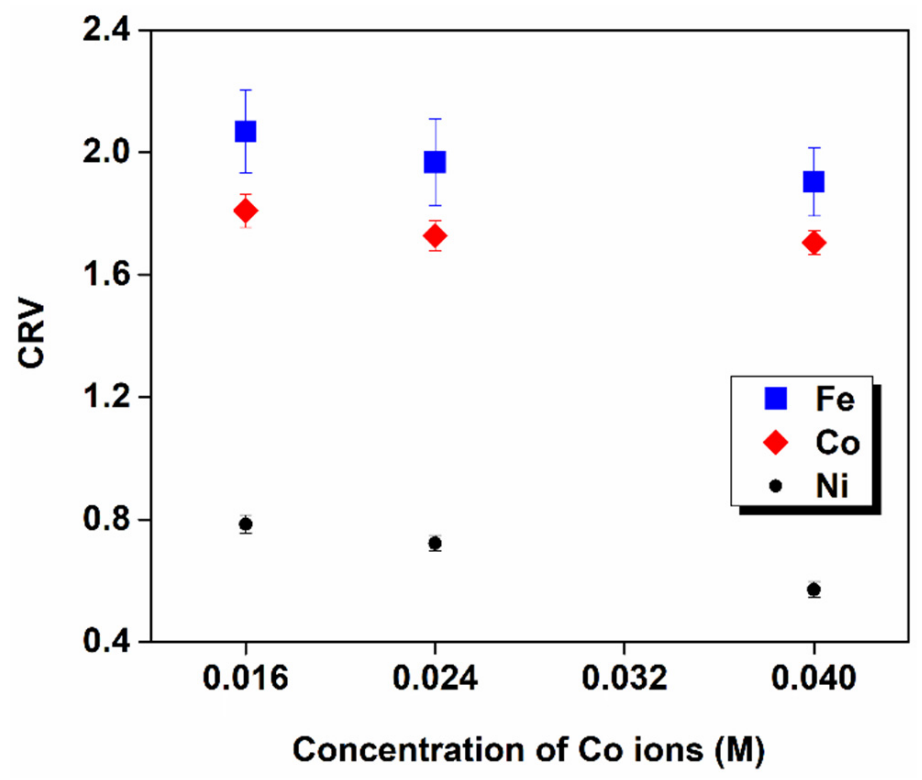

Figure 3. The $\mathrm{CRV}_{\mathrm{Fe}}, \mathrm{CRV}_{\mathrm{Co}}$ and $\mathrm{CRV}_{\mathrm{Ni}}$ as a function of the Co ion concentration in the PS.

The phase structure of the samples produced in this work was investigated via XRD analysis. The resulting XRD patterns are shown in Figure 4.

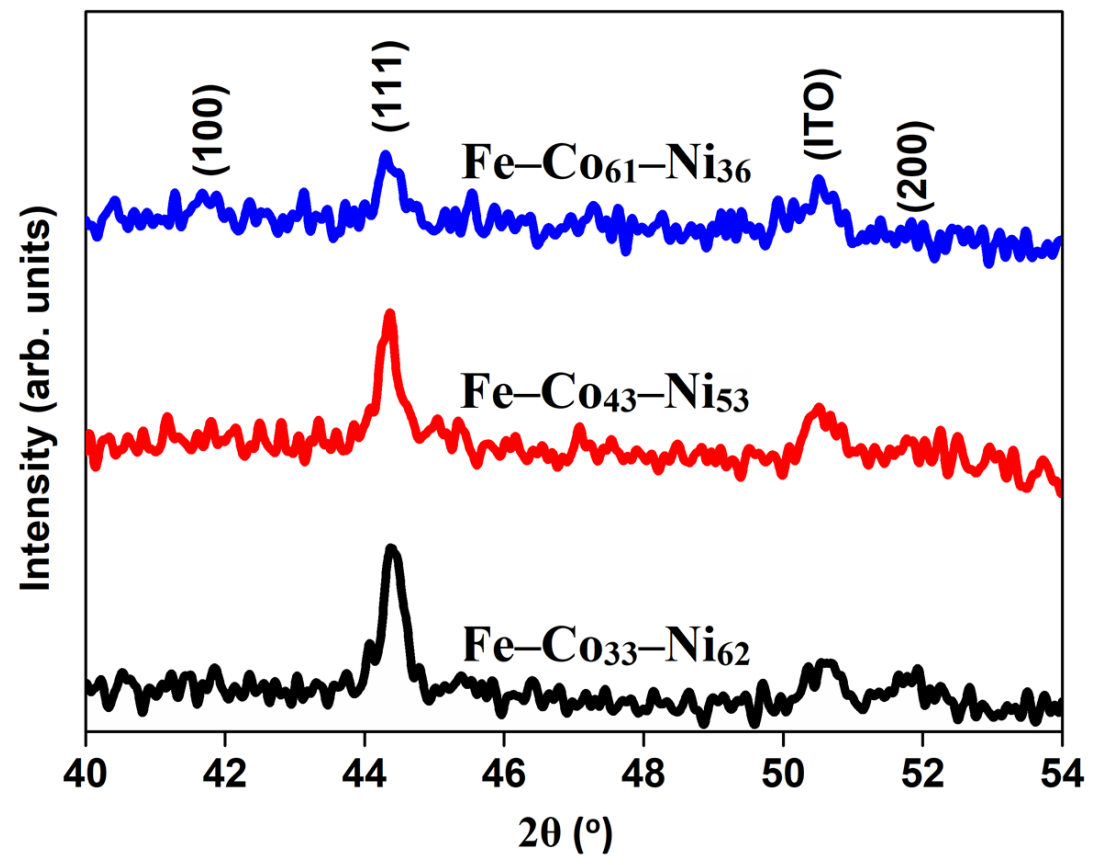

Figure 4. XRD patterns of the samples.

Obviously, in all samples, the (111) diffraction peak of the face-centered cubic (fcc) crystal structure observed at the angular position of about $2 \theta=44.4^{\circ}$ was the most intense irrespective of the Co contents. The single phase structure (fcc) obtained for the $\mathrm{Fe}-\mathrm{CO}_{33}-\mathrm{Ni}_{62}$ and $\mathrm{Fe}-\mathrm{Co}_{43}-\mathrm{Ni}_{53}$ samples shows a good agreement with the XRD patterns of the ternary ferromagnetic materials with similar compositions produced in previous studies $[6,21,24,54,55]$. In addition to that, compared to the $\mathrm{Fe}-\mathrm{Co}_{33}-\mathrm{Ni}_{62}$ and $\mathrm{Fe}-\mathrm{Co}_{43}-\mathrm{Ni}_{53}$ samples, the XRD pattern of the $\mathrm{Fe}-\mathrm{Co}_{61}-\mathrm{Ni}_{36}$ sample also revealed the presence of the (100) diffraction peak with low intensity related to the hexagonal close-packed (hcp) phase structure which occurred at about $2 \theta=41.7^{\circ}$. At high Co contents, a transition from single phase structure $(\mathrm{fcc})$ to dual phase structure ( $\mathrm{fcc}+$ hcp or $\mathrm{fcc}+\mathrm{bcc}$ ) was also reported 
in electrochemically grown binary $\mathrm{Ni}-\mathrm{Co}$ films, $\mathrm{Co}-\mathrm{Ni}-\mathrm{Al}_{2} \mathrm{O}_{3}$ composite coatings, and ternary ferromagnetic films of $\mathrm{Fe}, \mathrm{Co}$, and $\mathrm{Ni}[12,13,17,47,56]$. Alongside the phase transition, an increment in the Co contents resulted in a significant decrement in the intensities of both (111) and (200) diffraction peaks, reflecting a strong reduction in the crystallization (Figure 4). This also caused a change in the crystallite size of the samples. The crystallite size (D) of the produced samples was determined by Scherrer's equation [57]:

$$
\mathrm{D}=[0.9 \lambda / \mathrm{B} \cos \theta] \times\left[180^{\circ} / \pi\right]
$$

where $\lambda, B$ and $\theta$ represent the wavelength of $\mathrm{CuK} \alpha$ radiation, Full-Width at Half Maximum (FWHM) value, and Bragg diffraction angle, respectively. To estimate the B and $\theta$ values, XRD patterns were fitted by Lorentzian curves. It was revealed that mean crystallite size decreases from 21.6 to $15.6 \mathrm{~nm}$ as the Co contents in the samples increases from 33 to $61 \mathrm{wt} . \%$, indicating that the crystallite size of the Co-rich samples is smaller compared to the Co-poor samples. The decrease in the crystallite size with the Co contents was also reported in Fe-Co-Ni films electroplated on copper substrates from ammonium-chloridebased PSs [47]. The cause of the increase (decrease) in the size of Fe-Co-Ni is due to the lattice constant of $\mathrm{Fe}, \mathrm{Co}$, and $\mathrm{Ni}$ atoms and the interaction between electrons leads to the appearance of size effect. The 3-D surface microtexture can be characterized for a deeper understanding of the nano-scale patterns by stereometric [58-60] and fractal/multifractal analyses [61-64].

The surface topography was studied by means of SEM images analysis of the samples. The SEM device we used has a resolution of $100 \mathrm{KX}$, the crystals can be observed in Figure 5.

(a)

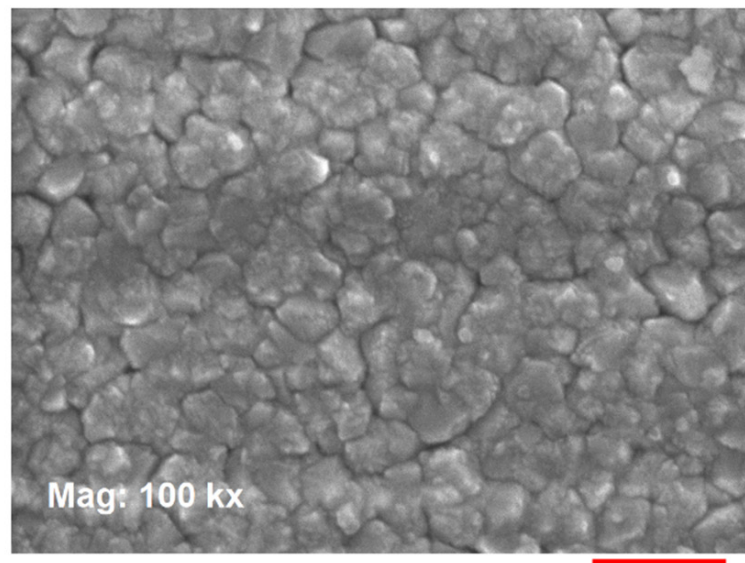

(b)

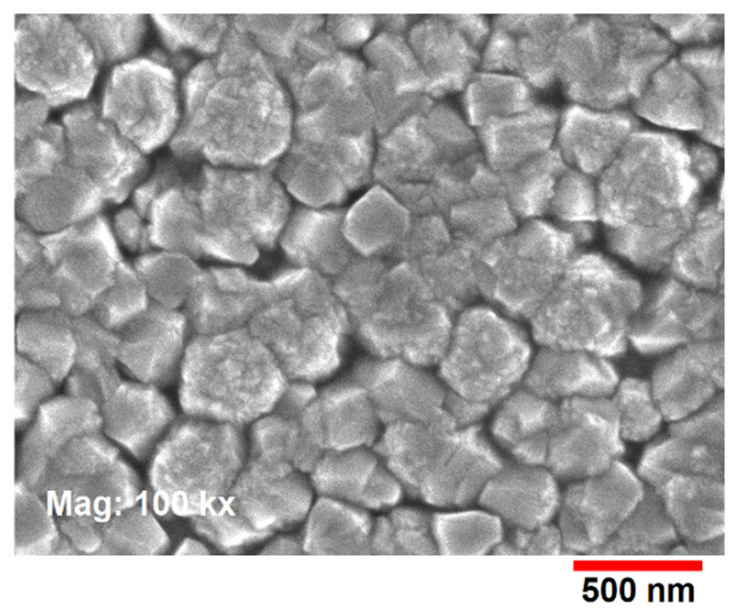

(c)

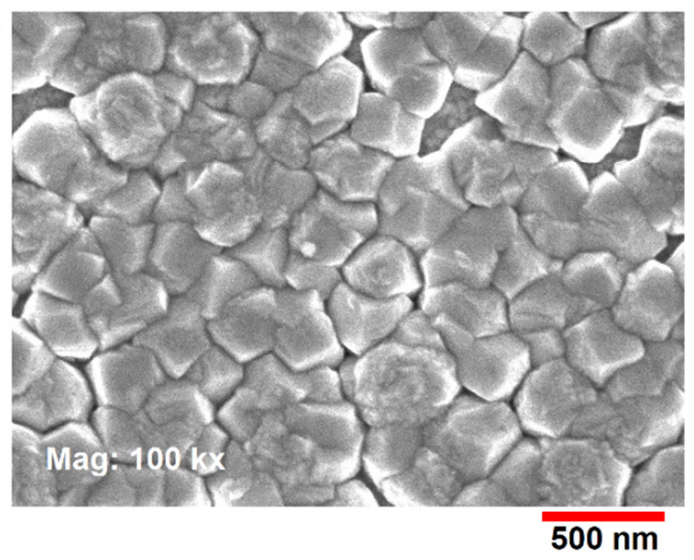

Figure 5. SEM images of the samples $\mathrm{Fe}-\mathrm{Co}_{33}-\mathrm{Ni}_{62}$ (a), $\mathrm{Fe}-\mathrm{Co}_{43}-\mathrm{Ni}_{53}$ (b), and $\mathrm{Fe}-\mathrm{Co}_{61}-$ $\mathrm{Ni}_{36}(\mathrm{c})$, respectively. 
Figure 5a showed that the $\mathrm{Fe}-\mathrm{Co}_{33}-\mathrm{Ni}_{62}$ sample exhibits a surface topography comprising only cauliflower-like agglomerates.

However, as seen from Figure $5 b, c$, the $\mathrm{Fe}-\mathrm{Co}_{43}-\mathrm{Ni}_{53}$ and $\mathrm{Fe}-\mathrm{Co}_{61}-\mathrm{Ni}_{36}$ samples had a surface topography covered with a mixture of pyramidal particles and cauliflower-like agglomerates. The surface morphology of a material is due to the lattice constant, the electronic interactions between different atoms caused.

In all samples, one cauliflower-like agglomerate was composed of grains. An increment in the Co contents caused an enhancement in the size of the cauliflower-like agglomerates and a decrease in their number. The average width of the cauliflower-like agglomerates was found to be about $150 \mathrm{~nm}$ for the $\mathrm{Fe}-\mathrm{Co}_{33}-\mathrm{Ni}_{62}$ sample. However, the $\mathrm{Fe}-\mathrm{Co}_{43}-\mathrm{Ni}_{53}$ and $\mathrm{Fe}-\mathrm{Co}_{61}-\mathrm{Ni}_{36}$ samples had larger cauliflower-like agglomerates with an average width of about 270 and $350 \mathrm{~nm}$, respectively. The size of the crystal nuclei is larger than the average size of the particles. The cause of this phenomenon is due to the difference between the lattice constants and the interactions between the electronic structures which leads to the formation of nuclei crystallization in the form of cauliflower.

On the other hand, the average width of the pyramidal particles was determined to be about 190 and $220 \mathrm{~nm}$ for the $\mathrm{Fe}-\mathrm{Co}_{43}-\mathrm{Ni}_{53}$ and $\mathrm{Fe}-\mathrm{Co}_{61}-\mathrm{Ni}_{36}$ samples, respectively. Thus, the $\mathrm{Fe}-\mathrm{Co}_{61}-\mathrm{Ni}_{36}$ sample exhibited larger pyramidal particles than the $\mathrm{Fe}-\mathrm{Co}_{43}-\mathrm{Ni}_{53}$ sample. Consequently, as also listed in Table 1, the $\mathrm{Fe}-\mathrm{Co}_{33}-\mathrm{Ni}_{62}, \mathrm{Fe}-\mathrm{Co}_{43}-\mathrm{Ni}_{53}$ and $\mathrm{Fe}-$ $\mathrm{Co}_{61}-\mathrm{Ni}_{36}$ samples had particles with an average width of approximately 150, 210, and $250 \mathrm{~nm}$, respectively, which was in good agreement with the findings reported in the literature [47]. Further studies on the morphological characteristics were also carried out using an AFM. Figure 6 indicates the AFM images of the samples. The samples possessed globular particles of various sizes. The size of globular particles increased and their number decreased when the Co content increased, which is consistent with the findings of the SEM analysis. The surface morphology of the material is caused by the lattice constant, the electronic force of interaction between the atoms of the material. On the other hand, the influence of the Co content on the particle size can be ascribed to different cathode potentials caused by the concentration of Co ions in the PS. Conducted studies showed that the particle size decreased when the cathode potential was increased [24].

(a)
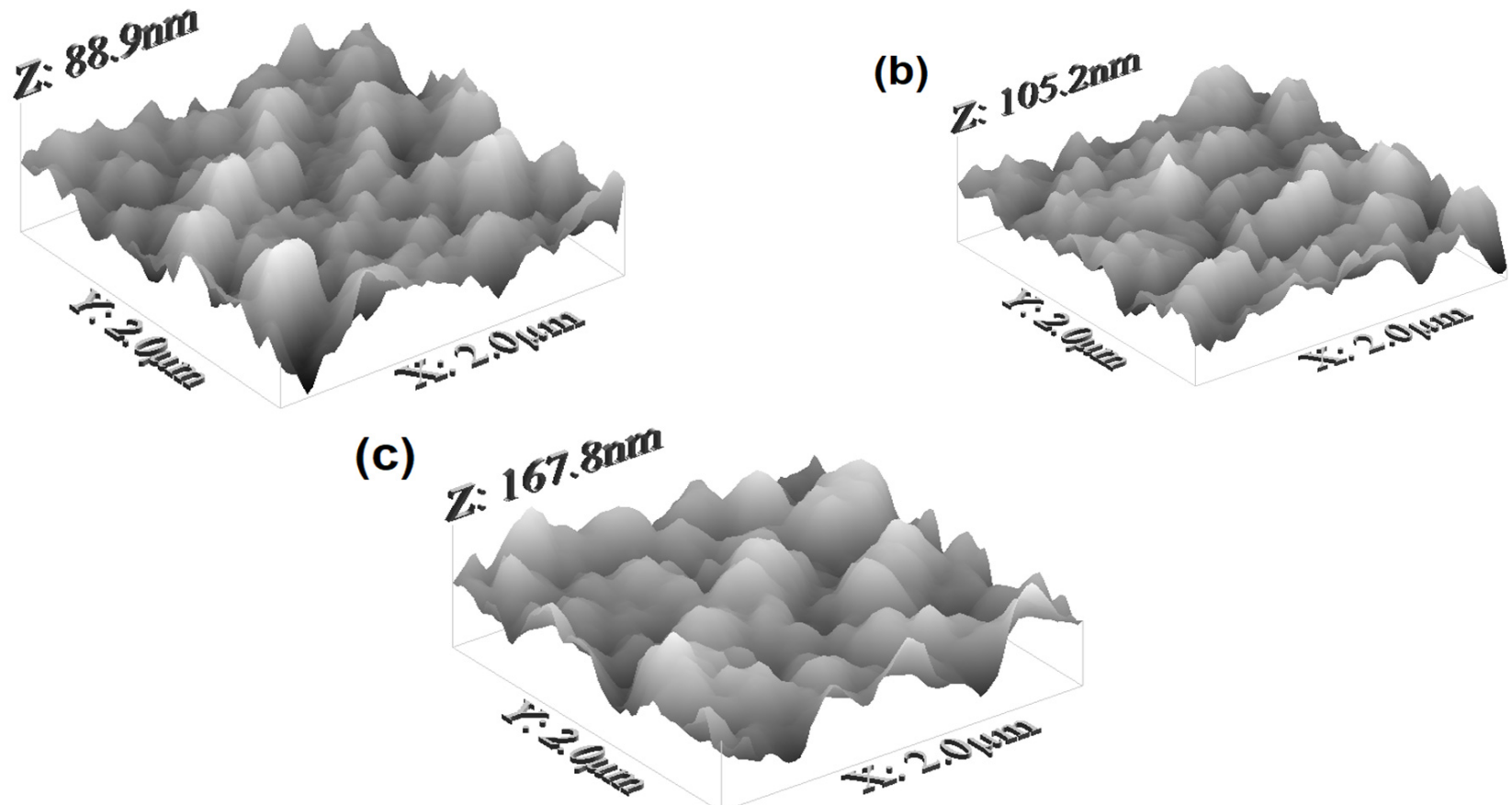

Figure 6. AFM images of the samples (a) $\mathrm{Fe}-\mathrm{Co}_{33}-\mathrm{Ni}_{62}$, (b) $\mathrm{Fe}-\mathrm{Co}_{43}-\mathrm{Ni}_{53}$, and (c) $\mathrm{Fe}-\mathrm{Co}_{61}-$ $\mathrm{Ni}_{36}$, respectively. 
Therefore, the particle size increased with the Co content since the cathode potential decreased with increasing Co ion concentration in the PS (Figure 1). The roughness parameters were determined from the AFM images. As distinctly noticed in Table 1, the Co content had a significant effect on the surface roughness parameters. When the Co content in the samples increases, the electronic interaction of Co with Fe and Ni increases, so the size of crystal nuclei increases, and the number of spheres is reduced leading to the increased surface roughness of the material.

Figure 6 indicates the AFM images of the samples. The samples possessed globular particles of various sizes.

The obtained results revealed that the surface roughness increased the cause is due to when Co content increased, leading to the electronic interaction of Co atoms with Fe, $\mathrm{Ni}$ increases, and the size of crystal nuclei increases and the number of spheres reduces to increased surface roughness of the material.

In this paper, the thickness and size of the considered thin films are not investigated especially, but the thickness of the thin film has an average size equal to the size of the crystal nuclei such as: $150 \mathrm{~nm}$ with $\mathrm{Fe}-\mathrm{Co}_{33}-\mathrm{Ni}_{62}, 270 \mathrm{~nm}$ with $\mathrm{Fe}-\mathrm{Co}_{43}-\mathrm{Ni}_{53}$, and $350 \mathrm{~nm}$ with $\mathrm{Fe}-\mathrm{Co}_{61}-\mathrm{Ni}_{36}$.

Figure 7 exhibits the normalized in-plane magnetic hysteresis loops measured to determine the magnetic characteristics with respect to their Co contents. The results obtained from the magnetic analysis are collected in Table 1. Although all samples exhibited a ferromagnetic behavior with a magnetic hardness being between soft and hard $[3,17,21,22,24,55,65]$, the Co contents played a significant role in the coercive field. The coercive field increased considerably from 36 to 121 Oe as the Co contents in the samples increased from 33 to $61 \mathrm{wt}$ \%. Increasing the content of Co leads to increased crystallization, increasing the size of the crystal nuclei (magnetic domain) leading to an increase in the coercive field of the material, which is shown in Figure 7. The increase in the coercive field with the Co content may also be attributed to an increment in the surface roughness.

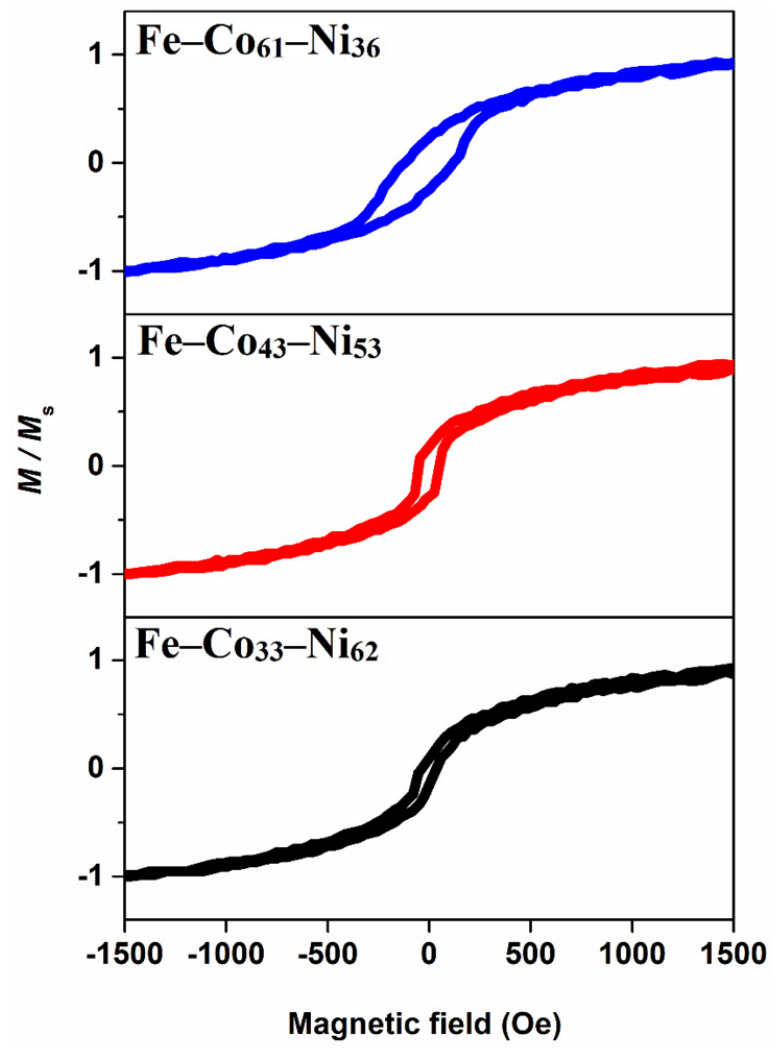

Figure 7. Hysteresis loops of the samples with different compositions. 
The variations observed in the average surface roughness and coercive field with respect to the Co contents are shown in Figure 8.

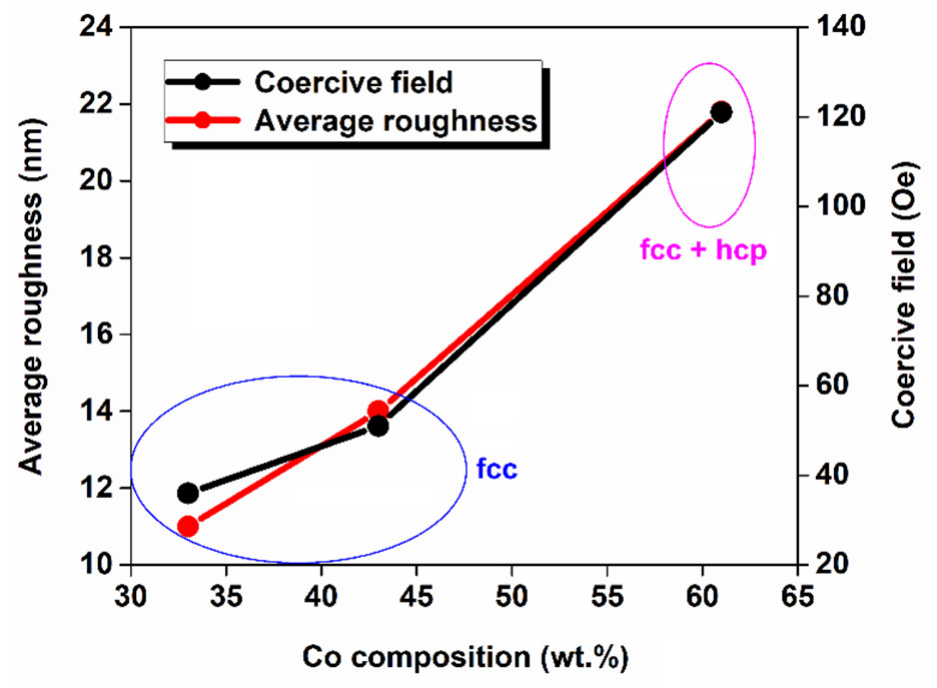

Figure 8. The correlation between the coercive field and the surface roughness.

As clearly evidenced in Figure 8, there was a direct correlation between the surface roughness and the coercive field as also reported in the electrochemically deposited ternary ferromagnetic films of $\mathrm{Fe}, \mathrm{Co}$, and $\mathrm{Ni}[21,24,65,66]$. In addiiton, the $\mathrm{Fe}-\mathrm{C}_{\mathrm{o} 61}-\mathrm{Ni}_{36}$ sample had a much higher coercive field than the $\mathrm{Fe}-\mathrm{Co}_{33}-\mathrm{Ni}_{62}$ and $\mathrm{Fe}-\mathrm{Co}_{43}-\mathrm{Ni}_{53}$ samples. This abrupt increase in the coercive field with increasing Co contents from 43 to 61 wt. \% may also be ascribed to the appearance of the (100) diffraction peak of the hcp phase structure of Co. In previous studies $[13,17,47]$, it was shown that the Ni-Co and Fe-Co-Ni films with single phase structure at low Co contents exhibit a much lower coercive field than the $\mathrm{Ni}-\mathrm{Co}$ and $\mathrm{Fe}-\mathrm{Co}-\mathrm{Ni}$ films with dual phase structure at high Co contents. On the other hand, the produced samples were found to have very low squareness ratios ranging from 9.2 to $23.6 \%$. Such low squareness ratios correspond to the formation of an in-plane hysteresis loop with a vertical magnetization component as also observed in electroplated $\mathrm{Ni}-\mathrm{Co} / \mathrm{ITO}$ and Fe-Co-Ni/ITO thin film samples $[21,65]$. Furthermore, as clearly seen from Table 1, a gradual increment in the magnetic squareness ratio was detected with the Co contents, revealing a decrement in the vertical component of magnetization.

\section{Conclusions}

This work aimed to obtain the ternary Fe-Co-Ni samples with various Co contents and reveal the differences in the morphological, magnetic, and structural properties with respect to their Co contents. According to the compositional analysis, a change in the Co ion concentration of the PS significantly affected the deposit composition. It was understood that the Fe-Co-Ni sample with higher Co contents could be obtained when the sample was electrochemically deposited from the PS including higher Co ion concentration. It was also revealed that the co-deposition characteristic (anomalous) and its order ( $\mathrm{Fe}-\mathrm{Ni}>\mathrm{Co}-\mathrm{Ni}>$ Fe-Co) were not affected by the amount of Co ions in the PS. The resultant samples exhibited the predominant reflection from the (111) plane of the fcc crystal structure. Unlike the $\mathrm{Fe}-\mathrm{Co}_{33}-\mathrm{Ni}_{62}$ and $\mathrm{Fe}-\mathrm{Co}_{43}-\mathrm{Ni}_{53}$ samples, the $\mathrm{Fe}-\mathrm{Co}_{61}-\mathrm{Ni}_{36}$ sample with the highest Co contents exhibited a weak reflection from the (100) plane of the hcp crystal structure of Co. Compared to the $\mathrm{Fe}-\mathrm{Co}_{61}-\mathrm{Ni}_{36}$ and $\mathrm{Fe}-\mathrm{CO}_{43}-\mathrm{Ni}_{53}$ samples, the crystallinity was found to be stronger for the $\mathrm{Fe}-\mathrm{Co}_{33}-\mathrm{Ni}_{62}$ sample. The size of the crystallites decreased from 21.6 to $15.6 \mathrm{~nm}$ as the Co contents in the sample increased from 33 to $61 \mathrm{wt} \%$. A surface structure covered with a mixture of pyramidal particles and cauliflower-like agglomerates was detected for the $\mathrm{Fe}-\mathrm{Co}_{43}-\mathrm{Ni}_{53}$ and $\mathrm{Fe}-\mathrm{Co}_{61}-\mathrm{Ni}_{36}$ samples, whereas the Fe$\mathrm{Co}_{33}-\mathrm{Ni}_{62}$ sample had a surface structure consisting of only cauliflower-like agglomerates. 
Moreover, compared to others, the $\mathrm{Fe}-\mathrm{Co}_{33}-\mathrm{Ni}_{62}$ sample exhibited a more compact surface morphology consisting of smaller cauliflower-like agglomerates with an average width of $150 \mathrm{~nm}$. As the Co contents enhanced, the average and RMS surface roughness parameters increased significantly from 11.0 to $21.8 \mathrm{~nm}$ and from 14.4 to $28.4 \mathrm{~nm}$, respectively. The samples produced were magnetically semi-hard. However, the $\mathrm{Fe}-\mathrm{Co}_{61}-\mathrm{Ni}_{36}(121 \mathrm{Oe})$ thin film sample exhibited a noticeably higher coercive field compared to the $\mathrm{Fe}-\mathrm{Co}_{43}-\mathrm{Ni}_{53}$ (51 Oe) and $\mathrm{Fe}-\mathrm{Co}_{33}-\mathrm{Ni}_{62}$ (36 Oe) thin film samples, which was attributed to the phase transition from single phase structure (fcc) to dual phase structure (fcc + hcp) and an abrupt enhancement in the surface roughness parameters. An increase in the Co contents from 33 to $61 \mathrm{wt} . \%$ also induced an enhancement in the magnetic squareness ratio from 9.2 to $23.6 \%$, reflecting a decrement in the vertical component of magnetization.

Author Contributions: V.C.L.: Validation, writing and editing. U.S.: conceptualization, methodology, investigation. M.C.B.: validation, writing and editing. L.D.T.: writing and editing. Ş.Tु.: writingediting. D.N.T.: conceptualization, methodology, investigation, resources, supervision, writingoriginal draft-review and editing. All authors have read and agreed to the published version of the manuscript.

Funding: This research was financially supported by the Scientific Research Projects Commission of Bartın University under the project number 2018-FEN-A-021.

Institutional Review Board Statement: Not applicable.

Informed Consent Statement: Not applicable.

Data Availability Statement: The data that support the findings of this study are available from the corresponding author upon reasonable request.

Acknowledgments: The authors would like to thank Çağdaş Denizli for taking AFM images and Malik Kaya for his assistance in the electrodeposition process of the samples.

Conflicts of Interest: The authors declare no conflict of interest. The funders had no role in the design of the study; in the collection, analyses, or interpretation of data; in the writing of the manuscript, or in the decision to publish the results. Neither author has a financial or proprietary interest in any material or method mentioned.

\section{References}

1. Hemeda, O.M.; Tawfik, A.; El-Sayed, A.H.; Hamad, M.A. Synthesis and characterization of semi-crystalline NiCoP film. J. Supercond. Nov. Magn. 2015, 28, 3629-3632. [CrossRef]

2. Boubatra, M.; Azizi, A.; Schmerber, G.; Dinia, A. The influence of pH electrolyte on the electrochemical deposition and properties of nickel thin films. Ionics 2012, 18, 425-432. [CrossRef]

3. Ledwig, P.; Kac, M.; Kopia, A.; Falkus, J.; Dubiel, B. Microstructure and properties of electrodeposited nanocrystalline Ni-Co-Fe coatings. Materials 2021, 14, 3886. [CrossRef]

4. Betancourt-Cantera, L.G.; Sánchez-de Jesús, F.; Bolarín-Miró, A.M.; Gallegos-Melgar, A.; Mayen, J.; Betancourt-Cantera, J.A. Structural analysis and magnetic characterization of ternary alloys (Co-Fe-Ni) synthesized by mechanical alloying. J. Mater. Res. Technol. 2020, 9, 14969-14978. [CrossRef]

5. Milyaev, M.A.; Bannikova, N.S.; Naumova, L.I.; Proglyado, V.V.; Patrakov, E.I.; Glazunov, N.P.; Ustinov, V.V. Effective Co-rich ternary CoFeNi alloys for spintronics application. J. Alloys Compd. 2021, 854, 157171. [CrossRef]

6. Budi, S.; Manaf, A. The effects of saccharin on the electrodeposition of NiCoFe films on a flexible substrate. Mater. Res. Express 2021, 8, 086513. [CrossRef]

7. Kayani, Z.N.; Riaz, S.; Naseem, S. Structural and magnetic properties of FeCoNi thin films. Indian J. Phys. 2014, 88, 165-169. [CrossRef]

8. Safavi, M.S.; Tanhaei, M.; Ahmadipour, M.F.; Adli, R.G.; Mahdavi, S.; Walsh, F.C. Electrodeposited Ni-Co alloy-particle composite coatings: A comprehensive review. Surf. Coat. Technol. 2020, 382, 125153. [CrossRef]

9. Song, J.; Yoon, D.; Han, C.; Kim, D.; Park, D.; Myung, N. Electrodeposition characteristics and magnetic properties of CoFeNi thin film alloys. J. Korean Electrochem. Soc. 2002, 5, 17-20. [CrossRef]

10. Pingale, A.D.; Owhal, A.; Katarkar, A.S.; Belgamwar, S.U.; Rathore, J.S. Recent researches on Cu-Ni alloy matrix composites through electrodeposition and powder metallurgy methods: A review. Mater. Today Proc. 2021, 47, 3301-3308. [CrossRef]

11. Alizadeh, M.; Safaei, H. Characterization of Ni-Cu matrix, Al2O3 reinforced nano-composite coatings prepared by electrodeposition. Appl. Surf. Sci. 2018, 456, 195-203. [CrossRef] 
12. Sattawitchayapit, S.; Yordsri, V.; Panyavan, P.; Chookajorn, T. Solute and grain boundary strengthening effects in nanostructured Ni-Co alloys. Surf. Coat. Technol. 2021, 428, 127902. [CrossRef]

13. Tian, L.; Xu, J.; Qiang, C. The electrodeposition behaviors and magnetic properties of Ni-Co films. Appl. Surf. Sci. 2011, 257, 4689-4694. [CrossRef]

14. Su, X.; Qiang, C. Influence of $\mathrm{pH}$ and bath composition on properties of $\mathrm{Ni}-\mathrm{Fe}$ alloy films synthesized by electrodeposition. Bull. Mater. Sci. 2012, 35, 183-189. [CrossRef]

15. Saraç, U.; Baykul, M.C. Comparison of microstructural and morphological properties of electrodeposited Fe-Cu thin films with low and high Fe: Cu ratio. Adv. Mater. Sci. Eng. 2013, 2013, 971790. [CrossRef]

16. Saraç, U.; Baykul, M.C. Microstructural and morphological characterizations of nanocrystalline Ni-Cu-Fe thin films electrodeposited from electrolytes with different Fe ion concentrations. J. Mater. Sci. Mater. Electron. 2014, 25, 2554-2560. [CrossRef]

17. Saraç, U.; Baykul, M.C.; Uguz, Y. Differences observed in the phase structure, grain size-shape, and coercivity field of electrochemically deposited Ni-Co thin films with different Co contents. J. Supercond. Nov. Magn. 2015, 28, 3105-3110. [CrossRef]

18. Saraç, U.; Kaya, M.; Baykul, M.C. Synthesis of Ni-Fe thin films by electrochemical deposition technique and characterization of their microstructures and surface morphologies. Turk. J. Phys. 2017, 41, 536-544. [CrossRef]

19. Saraç, U.; Kaya, M.; Baykul, M.C. The influence of deposit composition controlled by changing the relative Fe ion concentration on properties of electroplated nanocrystalline Co-Fe-Cu ternary thin films. Turk. J. Phys. 2018, 42, 136-145.

20. Saraç, U.; Baykul, M.C. An investigation of structural properties and surface morphologies of electrochemically fabricated nanocrystalline Ni-Co-Cu/ITO deposits with different compositions. Turk. J. Phys. 2019, 43, 372-382.

21. Saraç, U.; Baykul, M.C. Studying structural, magnetic and morphological features of electrochemically fabricated thin films of Co-Ni-Fe with different Fe compositions. Thin Solid Films 2021, 736, 138901. [CrossRef]

22. Saraç, U.; Baykul, M.C.; Uguz, Y. The influence of applied current density on microstructural, magnetic, and morphological properties of electrodeposited nanocrystalline Ni-Co thin films. J. Supercond. Nov. Magn. 2015, 28, 1041-1045. [CrossRef]

23. Hanafi, I.; Daud, A.R.; Radiman, S. Potentiostatic electrodeposition of Co-Ni-Fe thin films from sulfate medium. J. Chem. Technol. Metall. 2016, 51, 547-555.

24. Saraç, U.; Kaya, M.; Baykul, M.C. A comparative study on microstructures, magnetic features and morphologies of ternary Fe-Co-Ni alloy thin films electrochemically fabricated at different deposition potentials. J. Supercond. Nov. Magn. 2019, 32, 917-923. [CrossRef]

25. Brenner, A. Electrodeposition of Alloys Principles and Practice; Academic Press: New York, NY, USA, 1963.

26. Dung, N.T.; Cuong, C.N.; Hung, V.T. Molecular dynamics study of microscopic structures, phase transitions and dynamic crystallization in Ni nanoparticles. RSC Adv. 2017, 7, 25406-25413.

27. Hue, D.T.M.; Coman, G.; Hoc, N.Q.; Dung, N.T. Influence of heating rate, temperature, pressure on the structure, and phase transition of amorphous Ni material: A molecular dynamics study. Heliyon 2020, 6, e05548.

28. Dung, N.T. Z-AXIS deformation method to investigate the influence of system size, structure phase transition on mechanical properties of bulk nickel. Mater. Chem. Phys. 2020, 252, 123275.

29. Dung, N.T.; van, C.L. Effects of number of atoms, shell thickness, and temperature on the structure of Fe nanoparticles amorphous by molecular dynamics method. Adv. Civ. Eng. 2021, 2021, 9976633.

30. Dung, N.T.; Phuong, N.T. Understanding the heterogeneous kinetics of Al nanoparticles by simulations method. J. Mol. Struct. 2020, 1218, 128498 .

31. Quoc, T.T.; Trong, D.N. Molecular dynamics factors affecting on the structure, phase transition of Al bulk. Phys. B Condens. Matter 2019, 570, 116-121. [CrossRef]

32. Dung, N.T.; van, C.L.; van, D.Q.; Tुălu, Ş. First-principles calculations of structural and electronic structural properties of Au-Cu alloys. J. Compos. Sci. 2022; in press.

33. Dung, N.T.; Cuong, N.C.; van, D.Q. Study on the effect of doping on lattice constant and electronic structure of bulk AuCu by the density functional theory. J. Multiscale Model. 2020, 11, 2030001.

34. Dung, N.T.; van, C.L. Factors affecting the depth of the Earth's surface on the heterogeneous dynamics of $\mathrm{Cu}_{1-\mathrm{x}} \mathrm{Ni}_{\mathrm{x}}$ alloy, $\mathrm{x}=0.1$, 0.3, 0.5, 0.7, 0.9 by molecular dynamics simulation method. Mater. Today Commun. 2021, 29, 102812.

35. Dung, N.T. Some factors affecting structure, transition phase and crystallized of CuNi nanoparticles. Am. J. Mod. Phys. 2017, 6, 66-75. [CrossRef]

36. Dung, N.T.; Phuong, N.T. Molecular dynamic study on factors influencing the structure, phase transition and crystallization process of $\mathrm{NiCu}_{6912}$ nanoparticle. Mater. Chem. Phys. 2020, 250, 123075.

37. Dung, N.T.; van, C.L.; Ţălu, Ş. The structure and crystallizing process of NiAu alloy: A molecular dynamics simulation method. J. Compos. Sci. 2021, 5, 18.

38. Hoc, N.Q.; Viet, L.H.; Dung, N.T. On the melting of defective FCC interstitial alloy $\gamma$-FeC under pressure up to 100 Gpa. J. Electron. Mater. 2020, 49, 910-916. [CrossRef]

39. Dung, N.T.; Kien, P.H.; Phuong, N.T. Simulation on the factors affecting the crystallization process of FeNi alloy by molecular dynamics. ACS Omega 2019, 4, 14605-14612.

40. Dung, N.T. Influence of impurity concentration, atomic number, temperature and tempering time on microstructure and phase transformation of $\mathrm{Ni}_{1-\mathrm{x}} \mathrm{Fe}_{\mathrm{x}}(\mathrm{x}=0: 1,0.3,0.5)$ nanoparticles. Mod. Phys. Lett. B 2018, 14, 1850204. [CrossRef] 
41. Van, C.L.; van, D.Q.; Dung, N.T. Ab initio calculations on the structural and electronic properties of AgAu alloys. ACS Omega 2020, 5, 31391-31397.

42. Dung, N.T.; Phuong, N.T. Factors affecting the structure, phase transition and crystallization process of AlNi nanoparticles J. Alloys Compd. 2020, 812, 152133.

43. Quoc, T.T.; Trong, D.N. Effect of heating rate, impurity concentration of Cu, atomic number, temperatures, time annealing temperature on the structure, crystallization temperature and crystallization process of $\mathrm{Ni}_{1-x} \mathrm{Cu}_{x}$ bulk; $x=0.1,0.3,0.5,0.7$. Int. . Mod. Phys. B 2018, 32, 1830009.

44. Dung, T.N.; Cuong, C.N.; Toan, T.N.; Hung, K.P. Factors on the magnetic properties of the iron nanoparticles by classical Heisenberg model. Phys. B 2018, 532, 144-148.

45. Dung, N.T.; van, C.L.; Tălu, S. the study of the influence of matrix, size, rotation angle, and magnetic field on the isothermal entropy, and the néel phase transition temperature of $\mathrm{Fe}_{2} \mathrm{O}_{3}$ nanocomposite thin films by the Monte-Carlo simulation method Coatings 2021, 11, 1209-1216.

46. Yang, Y. Preparation of Fe-Co-Ni ternary alloys with electrodeposition. Int. J. Electrochem. Sci. 2015, 10, 5164-5175.

47. Yanai, T.; Koda, K.; Kaji, J.; Aramaki, H.; Eguchi, K.; Takashima, K.; Nakano, M.; Fukunaga, H. Electroplated Fe-Co-Ni films prepared in ammonium-chloride-based plating baths. AIP Adv. 2018, 8, 056127. [CrossRef]

48. Omata, F. Magnetic properties of Fe-Co-Ni films with high saturation magnetization prepared by evaporation and electrodeposition. IEEE Transl. J. Magn. Jpn. 1990, 5, 17-28. [CrossRef]

49. Horcas, I.; Fernández, R.; Gómez-Rodríguez, J.M.; Colchero, J.; Gómez-Herrero, J.; Baro, A.M. WSXM: A software for scanning probe microscopy and a tool for nanotechnology. Rev. Sci. Instrum. 2007, 78, 013705. [CrossRef]

50. Tseng, Y.T.; Wu, G.X.; Lin, J.C.; Hwang, Y.R.; Wei, D.H.; Chang, S.Y.; Peng, K.C. Preparation of Co-Fe-Ni alloy micropillar by microanode-guided electroplating. J. Alloys Compd. 2021, 885, 160873. [CrossRef]

51. Zhang, Y.; Ivey, D.G. Electrodeposition of nanocrystalline CoFe soft magnetic thin films from citrate-stabilized baths. Mater. Chem. Phys. 2018, 204, 171-178. [CrossRef]

52. Qiang, C.; Xu, J.; Xiao, S.; Jiao, Y.; Zhang, Z.; Liu, Y.; Tian, L.; Zhou, Z. The influence of pH and bath composition on the properties of Fe-Co alloy film electrodeposition. Appl. Surf. Sci. 2010, 257, 1371-1376. [CrossRef]

53. Ramazani, A.; Almasi-Kashi, M.; Golafshan, E.; Arefpour, M. Magnetic behavior of as-deposited and annealed CoFe and CoFeCu nanowire arrays by ac-pulse electrodeposition. J. Cryst. Growth 2014, 402, 42-47. [CrossRef]

54. Budi, S.; Kurniawan, B.; Mott, D.M.; Maenosono, S.; Umar, A.A.; Manaf, A. Comparative trial of saccharin-added electrolyte for improving the structure of an electrodeposited magnetic FeCoNi thin film. Thin Solid Films 2017, 642, 51-57. [CrossRef]

55. Kockar, H.; Demirbas, O.; Kuru, H.; Alper, M.; Karaagac, O.; Haciismailoglu, M.; Ozergin, E. Electrodeposited NiCoFe films from electrolytes with different Fe ion concentrations. J. Magn. Magn. Mater. 2014, 360, 148-151. [CrossRef]

56. Wu, G.; Li, N.; Zhou, D.; Mitsuo, K. Electrodeposited Co-Ni-Al ${ }_{2} \mathrm{O}_{3}$ composite coatings. Surf. Coat. Technol. 2004, 176, 157-164. [CrossRef]

57. Wang, J.; Lei, W.; Deng, Y.; Xue, Z.; Qian, H.; Liu, W.; Li, X. Effect of current density on microstructure and corrosion resistance of Ni graphene oxide composite coating electrodeposited under supercritical carbon dioxide. Surf. Coat. Technol. 2019, 358, 765-774. [CrossRef]

58. Țălu, Ş. Micro and Nanoscale Characterization of Three Dimensional Surfaces. Basics and Applications; Napoca Star Publishing House: Cluj-Napoca, Romania, 2015.

59. Méndez, A.; Reyes, Y.; Trejo, G.; Stępień, K.; Ţălu, Ş. Micromorphological characterization of zinc/silver particle composite coatings. Microsc. Res. Tech. 2015, 78, 1082-1089. [CrossRef] [PubMed]

60. Grayeli-Korpi, A.R.; Luna, C.; Arman, A.; Ţălu, Ş. Influence of the oxygen partial pressure on the growth and optical properties of RF-sputtered anatase $\mathrm{TiO}_{2}$ thin films. Results Phys. 2017, 7, 3349-3352. [CrossRef]

61. Mwema, F.M.; Akinlabi, E.T.; Oladijo, O.P.; Fatoba, O.S.; Akinlabi, S.A.; Ţălu, Ş. Advances in manufacturing analysis: Fractal theory in modern manufacturing. In Modern Manufacturing Processes, 1st ed.; Kumar, K., Davim, J.P., Eds.; Woodhead Publishing Reviews: Mechanical Engineering Series; Elsevier: Amsterdam, The Netherlands, 2020; pp. 13-39. [CrossRef]

62. Țălu, Ş.; Stach, S.; Raoufi, D.; Hosseinpanahi, F. Film thickness efect on fractality of tin-doped In $2 \mathrm{O}_{3}$ thin films. Electron. Mater. Lett. 2015, 11, 749-757. [CrossRef]

63. Țălu, Ş.; Morozov, I.A.; Yadav, R.P. Multifractal analysis of sputtered indium tin oxide thin film surfaces. Appl. Surf. Sci. 2019, 484, 892-898. [CrossRef]

64. Ţălu, Ş.; Stach, S.; Ramazanov, S.; Sobola, D.; Ramazanov, G. Multifractal characterization of epitaxial silicon carbide on silicon. Mater. Sci.-Pol. 2017, 35, 539-547. [CrossRef]

65. Denizli, Ç.; Sarac, U.; Baykul, M.C. Controlling the surface morphologies, structural and magnetic properties of electrochemically fabricated Ni-Co thin film samples via seed layer deposition. J. Mater. Sci. Mater. Electron. 2020, 31, 4279-4286. [CrossRef]

66. Rhen, F.M.F.; Roy, S. Dependence of magnetic properties on micro-to nanostructure of CoNiFe films. J. Appl. Phys. 2008, 103, 103901. [CrossRef] 